\title{
Influence of teacher-student interactions on kindergarten children's developing gender identity within the Pakistani urban classroom culture
}

Almina Pardhan

Aga Khan University, almina.pardhan@aku.edu

Follow this and additional works at: https://ecommons.aku.edu/pakistan_ied_pdck

Part of the Educational Administration and Supervision Commons, and the Pre-Elementary, Early Childhood, Kindergarten Teacher Education Commons

\section{Recommended Citation}

Pardhan, A. (2011). Influence of teacher-student interactions on kindergarten children's developing gender identity within the Pakistani urban classroom culture. Early Child Development and Care, 181(7), 929-948. 
This article was downloaded by: [INASP - Pakistan (PERI)]

On: 11 September 2012, At: 04:43

Publisher: Routledge

Informa Ltd Registered in England and Wales Registered Number: 1072954 Registered

office: Mortimer House, 37-41 Mortimer Street, London W1T 3J H, UK

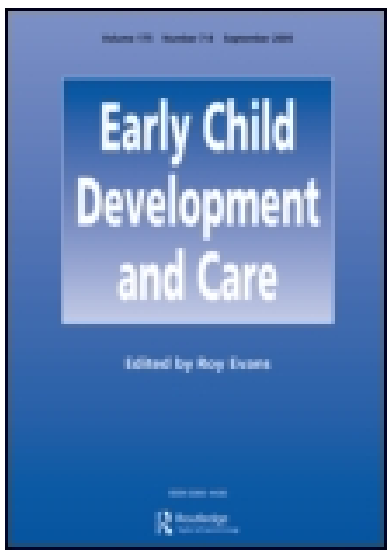

\title{
Early Child Development and Care
}

Publication details, including instructions for authors and subscription information:

http:// www.tandfonline.com/loi/gecd20

\section{Influence of teacher-student interactions on kindergarten children's developing gender identity within the Pakistani urban classroom culture}

\author{
Almina Pardhan ${ }^{a}$ \\ a Institute for Educational Development, Aga Khan University, \\ Karachi, Pakistan \\ Version of record first published: 24 May 2011.
}

To cite this article: Almina Pardhan (2011): Influence of teacher-student interactions on kindergarten children's developing gender identity within the Pakistani urban classroom culture, Early Child Development and Care, 181:7, 929-948

To link to this article: http:// dx.doi.org/ 10.1080/03004430.2010.504371

\section{PLEASE SCROLL DOWN FOR ARTICLE}

Full terms and conditions of use: http://www.tandfonline.com/page/terms-andconditions

This article may be used for research, teaching, and private study purposes. Any substantial or systematic reproduction, redistribution, reselling, loan, sub-licensing, systematic supply, or distribution in any form to anyone is expressly forbidden.

The publisher does not give any warranty express or implied or make any representation that the contents will be complete or accurate or up to date. The accuracy of any instructions, formulae, and drug doses should be independently verified with primary sources. The publisher shall not be liable for any loss, actions, claims, proceedings, demand, or costs or damages whatsoever or howsoever caused arising directly or indirectly in connection with or arising out of the use of this material. 


\title{
Influence of teacher-student interactions on kindergarten children's developing gender identity within the Pakistani urban classroom culture
}

\author{
Almina Pardhan* \\ Institute for Educational Development, Aga Khan University, Karachi, Pakistan \\ (Received 25 January 2010; final version received 23 June 2010)
}

\begin{abstract}
In the current global push to explore the diverse and complex ways in which the school culture contributes to the shaping of young children's gender identity, early childhood teachers' role in this process is an area of concern which has received limited attention. Furthermore, the schooling experiences of early years children in developing world contexts such as Pakistan remain largely absent. As such, this article discusses findings from a study investigating the role of women teachers' practice in the construction of children's gender identities in the kindergarten classroom culture of one urban co-education school in the highly gendersegregated Pakistani context. Seven teachers and approximately 120 children were involved. Data collection included teacher interviews and observations of teaching practice. Data were qualitatively and quantitatively analysed. The complex and dynamic nature of the gendered classroom culture reflected the teachers' active perpetuation of the dominant patriarchal ideologies in their practice. However, their practice also presented possibilities for change in unconscious and, occasionally, conscious attempts to push gender boundaries towards more equitable gender relationships. The teachers' gendered practice has significant implications for children's evolving gender identity construction.
\end{abstract}

Keywords: identity; culture; gender; classroom; children; teacher

\section{Introduction}

This article addresses an important issue from the Pakistani context related to the construction of young children's gender identity through teacher-student interactions in the classroom culture. This issue is significant on two fronts. First, young children's gender identity construction is being increasingly recognised as a complex and evolving process, with effects of class, language, race, ethnicity, religion and other categories overlapping in complicated ways to shape it (Robinson \& Jones Diaz, 2006). Teachers' perceptions and pedagogies are recognised as playing a key role in shaping young children's evolving gender identities. In the multicultural societies of the developed world, the engagement in ideas about the complex processes involved in young children's gender identity formation through their schooling experiences is evident in a growing body of work (Blaise, 2005; Hyun, 2007; Robinson \& Jones Diaz, 2006). However, the role that early childhood teachers play in the process of gender construction in young children's lives has

\footnotetext{
*Email: almina.pardhan@aku.edu
} 
received comparatively less attention than in other education sectors (Robinson \& Jones Diaz, 2006). Second, despite increased attention to the shaping of young children's gender identities in developed world contexts, a reflection of how young children's gender identities are shaped through their schooling experiences in diverse geographical regions of the developing world such as Pakistan remains obscure. Penn (2005) has argued that most of the world's children live in these contexts and their situation is very different from those conventionally studied in North America and Europe. With the rapid global expansion of early childhood education, exploring children's diverse experiences in school cultures in these contexts is of central concern (Penn, 2005).

In developing world contexts such as Pakistan, the expansion of early childhood education is intended to reduce social inequality by compensating for disadvantages arising from poverty, gender, ethnicity, language and religion (UNESCO, 2009). While investment in early childhood education and gender in Pakistan are key policy initiatives, global monitoring reports highlight slow and uneven progress (UNESCO, 2009). Gender inequity in education, largely to the disadvantage of girls, is mainly considered in relation to school enrolment and achievement, and research rarely addresses the ways in which gender informs the lived experiences of young children within the school and classroom culture in the patriarchal and hierarchical context of Pakistan.

This article attempts to address this silence by reporting a study of the interactions of women kindergarten teachers with their five-year-old students in the city of Karachi. While the focus of the study is on one school, it speaks to the broader literature of gender in early childhood education that argues for a deeper understanding of the processes which shape young children's gender identities in classrooms (Robinson \& Jones Diaz, 2006). The article begins by 'unpacking' the constructs of school culture, gender and identity, and by describing the research context and methods. The study's findings demonstrate the kindergarten teachers' gendered practice towards their fiveyear-old students, and the article concludes by suggesting the implications of such practice for young children's identity construction.

\section{The complexity of gender identity}

In the field of early childhood education, ideas about self-identity and culture are being increasingly recognised as complex and problematic (Brooker \& Woodhead, 2008; Penn, 2005). The understanding of the concept of children's identity has changed as children are seen to acquire more than a unique and simple identity in childhood. In today's world, children are perceived to acquire a complex bundle of interrelated, dynamic and, at times, competing identities, shaped by the local environment and values; the unique developmental niches that they inhabit; and their encounters with a succession of microsystems during the course of their daily lives at home and at school (Brooker \& Woodhead, 2008). There is widespread recognition of children's own agency in forming their identities and of their ability to draw on different 'selves' in the diverse circumstances they encounter (Brooker \& Woodhead, 2008). The need for greater understanding of the ways in which children's identities are mediated through power relations associated with race, ethnicity, culture, class and gender is emphasised in the literature (Robinson \& Jones Diaz, 2006), which warns of the risk of essentialising children's identity (Brooker \& Woodhead, 2008). 
Until the mid-twentieth century, theoretical explanations of 'gender' drew on a sex differences perspective which viewed gender formation as essentialist and biological, a perspective which was critiqued for failing to consider the complex, dynamic nature of gender and its intersection with factors such as race, ethnicity, culture and class (Biklen \& Pollard, 2001). A subsequent theoretical shift described the social construction of gender, while recent post-structural work has emphasised the discursive construction of meanings and their relationships to power, difference and privilege, and recognises individuals, including young children, as active agents in the construction of their own gendered identities within the constraints of particular cultural contexts (Blaise, 2005, 2010).

\section{The gendered nature of school and classroom cultures}

Contemporary gender theorising has helped to explain how these processes are shaped by both school and classroom cultures. 'School culture' is a multifaceted concept, composed of different dimensions and marked by the elusive, intangible construct of culture itself (Schoen \& Teddlie, 2008). Rogoff (2003), cautioning against simplistic interpretations, has defined culture as a set of beliefs, traditions, activities and practices which may be shared by members of a particular community; in this case, within the school community. Jayasuriya (2008) has also pointed out the active and fluid nature of culture which is constantly transformed by individuals in their communities, arguing that the constitutive concept of culture in shaping and patterning the forms of social interaction and exchange in a given society contributes to the formation of identity. This in turn determines the nature of social interaction (Jayasuriya, 2008). Clarke, Hall, Jefferson, and Roberts (1976) have presented a definition of culture which includes the 'map of meanings' through which the world is made intelligible to members of a group. This map of meanings is realised through patterns of social organisation and the way in which the social relations of a group are experienced, understood and interpreted (Clarke et al., 1976; Jackson, 1989). School culture, or the map of meanings in a school, constitutes the social context of schooling.

In this article, school and classroom cultures are understood as open, dynamic systems influenced by the espoused values and deep assumptions of the 'wider culture' of the society being served and resulting from multiple interpretations, interactions and negotiations of individuals and groups (Schoen \& Teddlie, 2008). Schooling is viewed as a space where existing cultural traditions within a society are transmitted or where existing and unjust cultural, political and economic structures are critically addressed, challenged and transformed (Schoen \& Teddlie, 2008). This raises fundamental questions about the nature of everyday teacher-student activities in the classroom. Nevertheless, Liu (2006) notes that identity issues related to gender continue to be glossed over by overriding managerial discourses concerned with 'school effectiveness' and 'school reform'. Understanding schooling at all educational levels, including in the early years, as a cultural practice puts gender relations directly in the dynamics of interaction between school and communities, with implications for the schooling experiences and post-school outcomes of both girls and boys.

Although each school may have its own particular culture, there is a dynamic process of gender at work in every school (Liu, 2006). Gender is embedded in school culture and helps to construct wider systems of meaning in the broader 
society (Liu, 2006; Renold, 2006). By and large, school culture, including in the early years of school life, operates to constitute, reflect and actively produce dominant gender relations in the wider society of hegemonic masculinity (Dobbs, Arnold, \& Doctoroff, 2004; Robinson \& Jones Diaz, 2006). This is apparent in all aspects of school life, including school organisation and management structures, relationships, teachers' perceptions, expectations and interactions with students, language, the curriculum, disciplinary methods, and students' own characteristics (Liu, 2006; Robinson \& Jones Diaz, 2006). Connell (2006) has argued that the privileged group which maintains control over resources reflects hegemonic masculinity and is maledominated; the marginalised group is made up of girls and women, non-heterosexual members, and those boys and men who choose not to or who fail to embrace hegemonic masculinity. While the institutional culture of the school defines gendered behaviour for its inhabitants, teachers and students play a key role in the way in which femininities and masculinities are mediated and lived out through actively negotiating and reproducing gender identities for themselves and others (Liu, 2006; Mac an Ghaill, 1994).

This is also evident in the emerging body of literature in early childhood education (Blaise, 2005; MacNaughton, 2000; Yelland \& Grieshaber, 1998). One area which remains under-researched, however, is the way in which teachers and children negotiate and reproduce gender identities through their interactions. As Dobbs et al. (2004) have argued, preschool boys receive more teacher attention than girls, but the different types of attention they receive remain an understudied area. The next section presents general findings on the gendered nature of teacher-student interactions and also highlights the few studies specific to early childhood settings.

\section{The construction of gender identity through classroom interactions}

One of the most powerful and subtle ways in which teachers shape students' gender identity is through teacher-student interactions within the classroom culture (Liu, 2006; Renold, 2006). Most research into gendered teacher-student interactions, however, focuses on work conducted in developed nations and at primary and secondary school levels. Nevertheless, this research together with the existing work from developing contexts and studies into the early years of school life has been fairly consistent in reflecting qualitative and quantitative gender differences in teachers' interactions with their students: boys get more teacher attention and dominate classroom space at all educational levels (Dobbs et al., 2004; Liu, 2006; MacNaughton, 2000; Miske \& VanBelle-Prouty, 1997; Quershi, Pirzado, \& Nasim, 2007). Compared with girls, boys dominate whole-class discussions; are disciplined, praised, instructed, responded to and listened to more; receive more helpful and constructive feedback; are asked more open, complex, higher-order questions; are given more challenges and strategies for problem solving; are perceived to be more disruptive and harder to handle; are assumed to be more intelligent and to have greater academic potential in general and, more specifically, in maths and science; and are viewed to be naturally stronger to face challenges as well as have a natural tendency to be better decisionmakers (Drudy \& Chathain, 2002; Halai, 2007; She, 2000; Skelton \& Francis, 2003; Zainulabidin, 2007).

In the existing though limited work on gendered teacher-student interactions in early childhood, similar patterns are evident. Boys get more teacher attention (Dobbs et al., 2004; Tantekin, 2002). They receive more commands and are disciplined more 
frequently and harshly than girls (Dobbs et al., 2004; Tantekin, 2002). Girls receive more positive interactions and rewards from teachers (Dobbs et al., 2004) and are in closer proximity to teachers (Colwell \& Lindsey, 2003). Early years' teachers also offer girls greater latitude in the exploration of behaviours and aspirations traditionally defined as 'masculine' than they do for boys transgressing conventional gender boundaries (Hyun \& Tyler, 2000). Hyun and Tyler's (2000) exploration of predominantly female preschool teachers' gender-biased perceptions found that male preschoolers' ways of playing, constructing knowledge and using knowledge were less appreciated. Boys were perceived to be 'builders', 'questioning', 'problemsolvers', 'hyper', 'crazy', 'outdoorsy', 'less teachable' and 'less easy to work with', while girls were viewed as positive and sensitive learners who were 'calm', 'nicer', 'teachable' and 'academic'. Girls were also perceived to be more passive and, hence, in need of adult/teacher-directed learning.

Boys' dominance in the classroom at all educational levels has been attributed to the tendency of teachers to view boys as more rewarding to teach, though harder to control; perceive boys as naturally more academically competent; and interact more with boys in an effort to engage them in work and/or to discipline them because they are more demanding and restless than girls (Miske \& VanBelleProuty, 1997; Skelton \& Francis, 2003; Tantekin, 2002). The influence of gendered teacher-student interactions on both girls and boys has raised concerns about their evolving identities and the impact on their future lives. Moreover, it has yielded important insights into analysing how the gendered nature of school culture characterised by male domination may disadvantage both girls and boys. However, Liu (2006) has cautioned against generalising from findings on teachers' gendered interactions with students and against treating girls and boys as two homogenous groups. Intersecting factors such as ethnicity, class and locality mediate gender in young children's schooling experiences (Dobbs et al., 2004; Hyun, 2007; MacNaughton, 2000).

\section{An overview of the research context}

Pakistan has distinct patriarchal and hierarchical social structures. Within the contextual norms, gender differentiation begins early, even before birth. Sons are preferred in the traditional patrilineal extended family structure. The well-being of sons is of great concern as the family's future providers and decision-makers (Ashraf, 2007). Consequently, they receive better family resources such as food, health care and education. They also experience greater freedom and mobility. Daughters are often considered a burden, living as 'guests' in their birth home until moving to their 'rightful' home after marriage, taking a dowry largely paid for by their parents' family. From childhood, daughters are groomed into the 'art of good housekeeping' (Bashiruddin, 2007, p. 44) and appropriate conduct as women. Their decision-making autonomy, mobility as well as access to and control of economic resources are highly constrained. Daughters' upbringing is an important preparation to take up subordinate roles of caregiving and domesticity, to secure suitable marriage partners and to ensure their suitable conduct in their marital homes. Local variants of Islam at times lead to adherence to strict rules regulating girls' behaviour as they move from childhood to womanhood when the perceived threat of a woman disgracing her family is more highly at stake (Ashraf, 2007). The powerful ideology linking family honor to female virtue restricts women's social mobility and interactions with non-relative men, 
especially in unsupervised circumstances, through purdah ${ }^{1}$ (literally, a veil) and gender segregation (Ashraf, 2007).

In pre-primary ${ }^{2}$ education, gender disparity in resource allocation and enrolment, to the disadvantage of girls and women, is evident. Pakistani women dominate preprimary education and, therefore, play an important role in young children's educational provision. Teaching in the early years is considered culturally appropriate and respectable for them. However, there is currently a dearth of pre-service teacher training institutions, and most women pre-primary teachers enter the profession with little, if any, training. Moreover, they teach in under-resourced classrooms, have low status and are amongst the lowest paid. Curriculum in pre-primary settings is predominantly academic and offered through a didactic pedagogy of direct instruction.

Pre-primary education data in Pakistan are neither regular nor comprehensive (Children's Resource International [CRI], 2008), but clearly demonstrate gender disparity. Of the approximately 8.61 million children in the three- to five-year age group, the net participation rate in pre-primary education is only $25 \%$, with the majority being male (Ministry of Education, 2003). Within the public sector, dropout rates are high between katchi (public sector pre-primary schooling) and Class 1 - about $37 \%$, with $35 \%$ for boys and 39\% for girls (CRI, 2008). Key factors responsible for the dropout rate include parents' limited understanding of the relevance of preprimary education, poverty, shift of residence, school distance, cultural norms constraining girls' access to school, and lack of teachers' attention and competency to teach katchi class children (CRI, 2008). While some private pre-primary schools provide relatively better quality education, these are inaccessible and unaffordable to most people, including the almost $70 \%$ of the population residing in rural areas (CRI, 2008).

\section{Methodology}

\section{Research site and sample}

The present study was conducted in four kindergarten classrooms at the private, coeducation, English-medium Rainbow School ${ }^{3}$ located in the urban city of Karachi, Pakistan, where the researcher is professionally situated as an early years teacher educator and researcher at a reputable university that supports local schools with school improvement. Language and Pakistan's current volatile political climate were key factors in selecting the research site. At the time of the study, the researcher had limited fluency in Urdu, the language most commonly used in Karachi and the national language of Pakistan. ${ }^{4}$ The researcher was also concerned about moving between multiple research settings, given the country's unpredictable political situation.

In a context where the research culture is in its infancy, entry into schools is largely negotiated through the fold of acquaintanceship. Consequently, access to the research site was facilitated through the researcher's previous work there as an early years teacher educator in the school's partnership with the university's early childhood education teacher development programme. Given the hierarchical nature of schools in this context where individuals like principals and coordinators have authority at different levels above teachers, access was first negotiated through the school principal. The researcher shared the project's methodology and ethical considerations with the principal, who approved the project and initiated the process for contact with 
the kindergarten teachers and children. In this cultural context with distinct gender boundaries, being a woman probably facilitated entry into the research setting which had only women teachers at the pre-primary level.

Each kindergarten classroom had approximately 30 students (almost equal distribution of girls and boys in each class) and one female teacher. Three female support teachers rotated between the four classrooms to assist each main class teacher. Kindergarten at Rainbow School is typical of Pakistani pre-primary establishments with a predominantly teacher-centred academic syllabus taught by teachers with little training. However, evident in kindergarten at Rainbow School is the attempt to break this mould by including one 40-minute period a week for unstructured play in learning areas based on the High/Scope Approach' of 'plan-work-recall'. 6

\section{Procedures}

The broad aim of the study was to explore how women kindergarten teachers understand the concept of gender as evident from their reflections and teaching practice with girls and boys. Data were collected from August 2006 to May 2007. Data collection methods included life history interviews and classroom observations. Each teacher was interviewed three to four times. Classroom observations of daily classroom routine activities began after the first interview with each teacher. Questions for the second and third interviews were further developed through these observations such that the teachers' reflections about their understanding of gender were connected to their gendered teaching practices. The duration of each classroom observation was 30 minutes. Each teacher was observed on 12 different days and at different times of the day which were randomly selected. The intention was to capture teacher-student interactions over enough time to give a reasonable sense of the types of interactions that typically occur during teachers' teaching practice and interactions with students (Tudge \& Hogan, 2005). Given the academic syllabus, 49 observations were made during teacher-centred lessons which involved mainly written tasks for children and seven observations were made during unstructured play periods in the learning areas. The observations were recorded using running records. Out of the 12 observations, four observations for each teacher were treated as pilot observations and were not included in the results. The pilot observations were important for the researcher to become familiar with the context and with the feasibility of the strategy to write running records. ${ }^{7}$

\section{Data analysis}

Data analysis was on-going, open-ended, continuously iterative and happened with different data sets at different levels (Miles \& Huberman, 1994). Interview data were analysed qualitatively. They were coded based on the research questions and literature, and from within the data itself. The researcher moved back and forth between interview data sets to refine the codes and categorise them into pattern codes from which themes were developed to consider with the observation data sets.

Data drawn from classroom observations were analysed qualitatively and quantitatively. Running records of observation data were analysed qualitatively using the same process as with interviews. Quantitative analysis began with observation data from one teacher to develop codes for categories of interaction events related to gender, taking into consideration keywords, phrases and interactions within chunks of 
data. After developing a preliminary coding scheme based on one classroom observation, the researcher combed through data from the other seven classroom observations of the teacher to further refine category codes. The researcher then engaged in a 'backand-forth' process between individual teacher data sets to further refine category codes, collapsing or adding additional ones. The observation coding scheme was based on the research questions and literature, and from within the data itself. The categories encompass various aspects of teacher-student interactions, including teacher question, teacher help, teacher response, teacher directive, teacher praise, behaviour management, teacher classroom task assignment, teacher gender language and teacher non-verbal interaction with students.

After the initial coding of the observation data was complete, the coding was checked again for accuracy. Two trained educational researchers reviewed the coding scheme to ensure that the category codes matched with the data. Their feedback was incorporated to make minor changes. Emerging patterns were identified from the refined codes to examine together with the interview data sets to develop themes for the writing process.

Frequencies for each teacher-child interaction were computed. In addition, one of the trained educational researchers mentioned earlier also checked for accuracy of counts. Ten percent of the observation data for two categories - behaviour management and teacher directives - were reviewed by a trained educational researcher with teacher education expertise for inter-rater reliability. ${ }^{8}$ This was to check whether this individual interpreted the coding scheme in the same way as the researcher had intended. Correlation was computed in order to explore overall inter-rater reliability. Inter-rater reliability was judged to be excellent $(r=0.99)$.

The primary objective of observation was to explore the teachers' gendered teaching practice with kindergarten girls and boys. Given the concern about breaching anonymity and confidentiality, the researcher combined frequency counts for all teachers to present the findings. A database was developed using the Statistical Package for the Social Sciences (SPSS) 16.0. The researcher then entered observational data for all categories. Data were explored at category level for girls and boys using descriptive analysis (mean score, standard deviation and range) both for overall observations (teacher-centred lessons plus weekly unstructured play episodes) and for play episodes only. A separate analysis for play episodes was carried out based on qualitative findings around teachers' perceptions of their gendered interaction with children during play. As discussed earlier, given that the observations were scheduled randomly, the researcher was only able to observe five teachers during play episodes which only took place once a week during daily routine activities.

To compare observation data, a paired $t$-test was used, although the author is aware that a paired $t$-test would typically not be carried out on such a small sample size. The results may not be generalised to all pre-primary classrooms in Pakistan. However, the results revealed interesting trends that reflect practices of the particular school in which the research was conducted.

\section{Ethical considerations}

Ethical approval was obtained through the University of Toronto's ethics review office. Informed consent was obtained from each teacher and consent was generously given. All the children in the class were asked for assent for the classroom observations involving teacher-student interactions. None of the children refused assent. 
Each child was assigned a participant number and no names of any children were used.

\section{Findings and discussion}

\section{Teachers' consideration of gender in their teaching practice}

The women teachers had all taken up teaching with no prior teacher training. None of their in-service professional development opportunities had addressed gender issues in education. In their planning thus far, gender had never been considered. This study was the teachers' first opportunity to reflect upon their teaching through a gender lens. For example, one teacher reflected:

To tell you the truth, you [researcher] are the first one that (has made me think) that this (gender) is something we have to look into ... I have attended many workshops ... but ... I never have got this chance ... to talk about this thing.

Consequently, their understandings and perceptions of gender were highly influenced by their lived experiences and fraught with tension. Although they attributed gender differences to be an interaction between biological - from Allah (God) - and social factors in the first instance, a deeper analysis reflected their understanding being largely influenced by discourses that naturalise and normalise gender behaviours in the biological differences between males and females. This was particularly evident in their views of children taking up traditional ways of being girls and boys, particularly as they got older, as part of a 'natural' process. For example, one teacher spoke about this in relation to her daughter and son. She shared:

I have one girl of my own who can be naughty like a boy and who can climb the tree ... now ... she (is growing) and has changed a lot ... she has become much sober ... I think by the time (my son) is going to grow up, he is also going to change, most probably he (is) going to be more naughty ... (B)y the time (girls and boys) start growing, its their nature ... they change.

The teachers' main position was that of treating girls and boys equally in the classroom in terms of opportunities, guidance, teaching methods, perceptions, support and time. Underlying this stance was their sense that in the early years of school life, there is not much difference between girls and boys; their attempt to comply with school policies of treating children equally; topics on gender in education having never been covered in their professional development; and the fact that they have never reflected deeply upon it before. The teachers did add that unconsciously they may not be treating girls and boys in the same way.

\section{Teachers' perceptions of their role in identity construction}

The women kindergarten teachers viewed their main role as establishing a sound foundation for their students that would have a lifetime impact on them and on society. According to them, girls and boys today, particularly in the cosmopolitan city of Karachi, are coming across different opportunities and circumstances in an increasingly technological society which they explained 'were not there previously'. They felt responsible for preparing children academically to compete and avail themselves of opportunities in this increasingly technical environment as well as for guiding 
children to be respectful, responsible citizens and stewards of the environment. However, a multi-layered struggle was evident in their classroom practice within the patriarchal structures of this increasingly global and technological environment complicated by local political instability, and teachers' practice revealed their tensions in maintaining deep-rooted patriarchal cultural values.

The teachers' practice revealed subtle attempts to resist prevailing gender norms in their advocacy for wider opportunities, education, and careers and opportunities for both girls and boys. They felt particularly concerned about contributing towards a better future for their female students compared with their own lives where possibilities for girls and women to take up higher education and careers were discouraged. All the same, they felt limited in the extent of their influence by other environmental factors and their own teaching pressures. The teachers felt that the future of their female students would still be by and large determined by others, including their birth and marital families. As such, they saw it as their responsibility to teach girls the art of patience to deal with uncertain life circumstances and to manage multiple commitments as women. For example, during a lesson on professions, some girls expressed their interest to become teachers. The teacher responded: 'See Aunty ${ }^{9}$ works at home even, so she is not only a teacher. She is a mother; she has got responsibilities'.

For the most part, however, the teachers' deeply espoused gender beliefs and religious interpretations of male privilege reflected the tensions within the broader socio-political context, and their practice highlighted the perpetuation and maintenance of existing patriarchal gender images. The teachers felt it their responsibility to guide children to take up socially approved codes of gender conduct for their future when this would become important. As one teacher shared:

Obviously boys tend to be responsible for earning ... and girls ... are there for looking after the house and the children ... (These) are the main responsibilities which (boys and girls) have to take. So obviously we have to develop that as ... teachers.

During their interactions with children, the researcher often heard the teachers instructing boys to get 'troop cuts', 'stiffen up' and 'sit straight' like soldiers. The interview data showed that the teachers perceived their own conduct in terms of how they sat and covered their head with a dupatta ${ }^{10}$ or scarf to be a role model to girls. Although equal opportunities for girls and boys such as participating in non-gender stereotypical play were advocated, when this happened during play, especially with boys, this raised concern for the teachers. They humorously shared with colleagues when boys dressed up like girls or cooked; when girls made trains in the block area, this did not usually become a topic of discussion. This corroborates earlier findings that teachers offer girls more latitude in their exploration of behaviours and aspirations (Hyun \& Tyler, 2000) and reflects the teachers' unreadiness to cope with the impact of social change and its consequences for their role and position as women teachers.

Their sense of responsibility for facilitating children's gender development according to culturally approved norms was derived from their views shared in the interviews of young children's 'innocence', 'inability to understand' and 'unawareness' of belonging to different sexes. Robinson and Jones Diaz (2006) have noted similar findings in their research where educators distanced children from broader gendered structures founded in dominant social discourses that perpetuate developmental understandings of children as being 'too young' to understand or 'too innocent' to be subjected to the burdens of what are perceived to be adults' concerns. 


\section{Teacher-student interactions: qualitative and quantitative differences}

The nature of the kindergarten teachers' gendered interactions with their male and female students are summarised here; they both reflected gender stereotypes and revealed the powerful yet subtle influence which the teachers exerted over their students.

\section{Boys get more attention academically}

The teachers viewed girls as more academically inclined and boys as less so, yet they persisted in an unconscious belief that boys were naturally more able generally and in maths and science in particular, and only failed due to lack of effort. Girls' academic success was perceived to be through effort. For example, one teacher noted:

If there is something ... the girls would (need to) spend five to ten minutes on it. The boys might (only need to) give five minutes (to the task) if they concentrate and they would get it.

This finding offers further evidence that such gender biases may lead to girls blaming their poor performance on a lack of ability rather than a lack of effort, with far reaching effects on their performance in school and later (Liu, 2006; Skelton \& Francis, 2003).

Although the teachers felt that girls take longer to grasp concepts, they described girls to be more focused, hard-working, detailed, persistent and to take time to think. The teachers felt that these characteristics enabled girls to understand and retain concepts and perform well academically. Furthermore, girls are more inclined to seek teacher support. The teachers described boys as lacking concentration, being in a hurry, giving up easily and quickly, being inattentive and easily distracted, speaking without thinking, and lacking seriousness about school and their work. The teachers felt that boys are less likely to seek teacher assistance, which limits their ability to fully grasp concepts. Consequently, boys require extra help, direction, guidance and support from teachers. As one teacher described:

Girls are good listeners ... more attentive ... detailed ... and hard-working ... When you ask girls, they take a lot of time to think ... they come to me and ask me (if they need help) ... Most of the boys, they are fidgety all the time; they don't listen (and) don't take care of others that much; they are always in a hurry ... The (boys) need more attention from me, so that's why I ... (give) my support to them. I know that they need my support. ... They won't ask me, (but) I know they need it.

Perhaps the teachers' views discussed earlier about their role to ensure that boys are prepared to take up eventual roles as family providers within contextual norms may have also influenced the greater support given to boys for their academic success.

Three types of teacher directives which were compared to explore the differences in the number of teacher interactions with girls and boys are shown in Figure 1. These differences reflect their views of boys as less academically oriented and in need of more academic support and direction. They are consistent with the qualitative data on teacher-student interactions in relation to gender, with boys receiving more teacher attention than girls. Teachers gave boys more directives related to academic learning outcomes than girls, for example directing a child during a maths lesson on counting to 'count the trees'. The difference was found to be significant $(t(6)=-2.645$, 


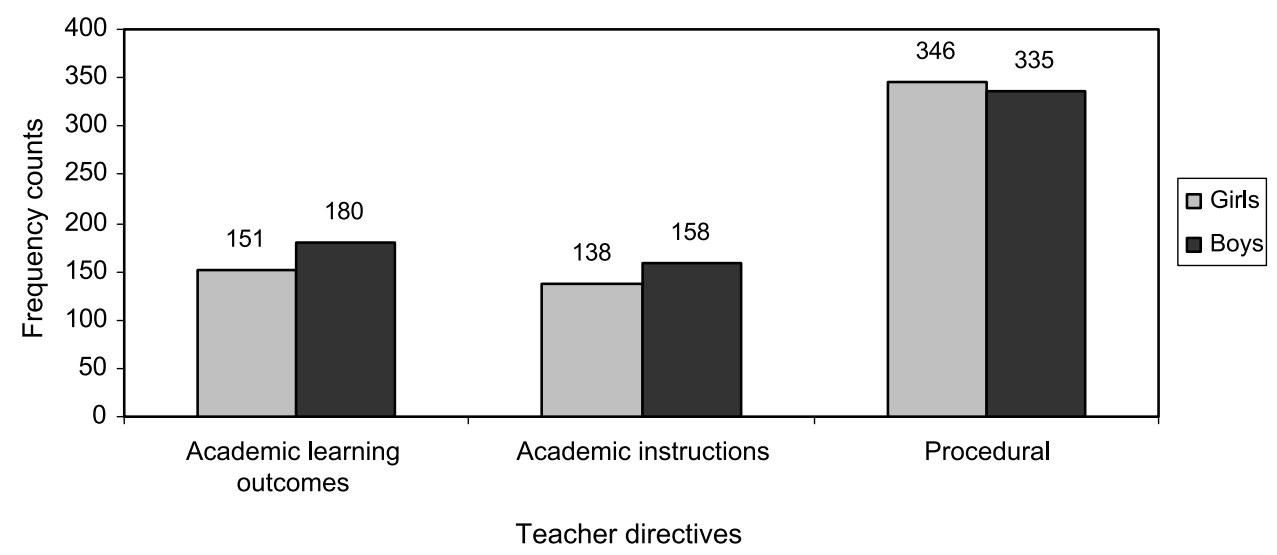

Figure 1. Teachers directives to kindergarten girls and boys.

$p<0.05)$. Teachers also gave boys more directives related to academic instructions than girls, for example directing a child to 'write quickly and neatly'. However, the difference was not significant. Boys and girls appeared to receive almost equal numbers of procedural directives, for example 'put your hand up'.

\section{Boys get more attention socially}

The teachers found boys' social behaviour to be more challenging than girls' in the classroom. They described boys as naughty, distractive, aggressive and rough; likely to use crude/bad language; and to have little respect for women teachers and female students. They expressed frustration at the amount of teaching-learning time taken up in disciplining boys:

I feel ... very irritated (with) them because the same thing happens ...with the boys. Girls, they don't bring you to that (point), they don't do that ... They (girls) do not want to be threatened by the teacher ... They (girls) know their limits, but the boys, they do cross their limits ... They want to see what Aunty is going to do because they know that Aunty won't hit - they know that. Since (nursery) they are in the school, they know that there was that Aunty (in nursery who) never scolded us that much ... so they take us for granted ... (Boys) don't listen ... they don't respect us (women teachers) and this is a ... problem in our society.

Some teachers struggled with the awareness that disciplining boys left little time to give to compliant, reserved children, usually girls.

The largely teacher-directed academic curriculum with limited opportunity for children to engage with concrete material was also perceived by a few teachers to affect boys' behaviour. These teachers felt that, compared with girls, boys are more engaged when they have something 'to hold and see'. As one teacher shared: 'When (boys) get bored ... they start disturbing others (like) ... pinching'.

Figure 2 shows differences in the total number of times teachers disciplined girls and boys for their social behaviour and for their academic behaviour. Results reflect consistency with the teachers' reports of disciplining boys' more and spending considerable time dealing with classroom discipline. Teachers disciplined boys' social behaviour more compared with girls, for example disruptive behaviour, and the 


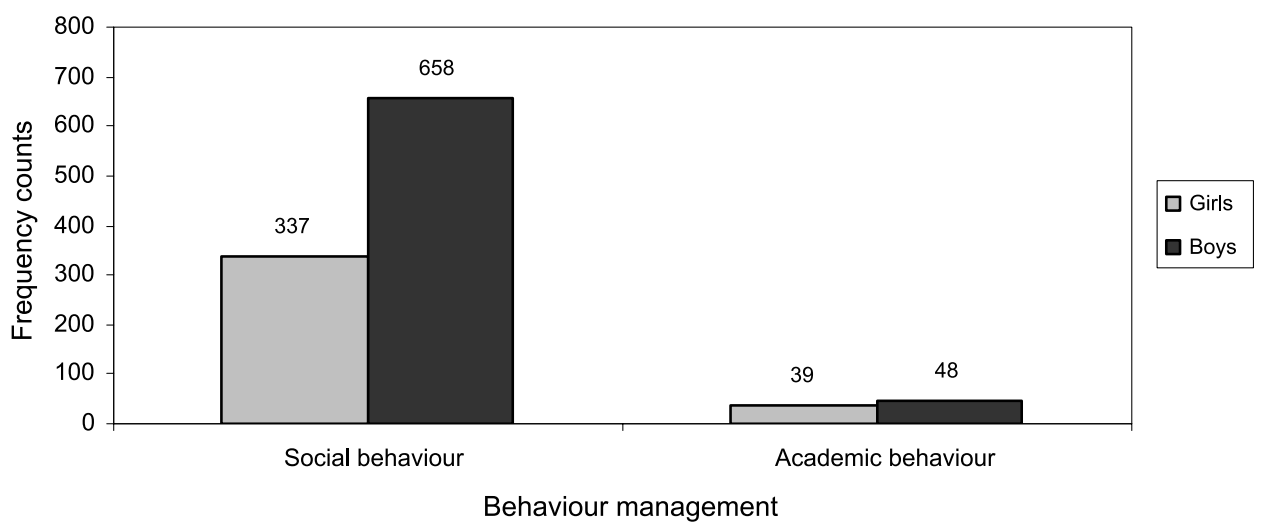

Figure 2. Behaviour management of kindergarten girls and boys by teachers.

difference was significant $(t(6)=-3.697, p<0.05)$. With regard to academic behaviour, for example, in disciplining a child for doing a task incorrectly, teachers appeared to discipline boys and girls almost equally.

Running records showed inconsistency in classroom rules and expectations such as teachers asking children to raise their hands and then accepting responses being called out, mainly by boys. This reflected the teachers' encouragement of boys' dominance and non-compliance. The teachers appeared to tolerate such behaviour as they felt it was how boys normally behave. However, they also shared that this behaviour from the boys was chaotic and frustrating at times. As one teacher described: 'Boys are quite hyper ... that's natural ... Sometimes I am very helpless with these ... behavioural problems ... I don't know what to do'.

When girls called out, they tended to be disciplined for not following rules and for being loud. Liu (2006) and Skelton and Francis (2003) also reported that girls' perceived misbehaviour raised concerns for teachers. This finding raises questions about the impact of such practice on children's understanding of their gendered selves.

Although the teachers' practice reflected privileging boys, they favoured girls as students. Their greater inclination towards girls in the classroom was because of their view that girls are generally calm, gentle, well-mannered and teachable. They wanted boys to be more composed and attentive towards completing their tasks and appreciated the few boys who behaved this way. This reflects how the school can be a site of conflict in gender role expectations for young boys to be dominant, achieving, independent and aggressive, but also quiet, conforming and model students. While it does not seem to conflict with traditional role expectations of girls being calm and compliant, their willingness to conform could have long-term negative consequences for their self-esteem and independence.

\section{Girls get some attention academically and socially}

While boys received more teacher attention and time academically and socially, girls were given some visibility, as reflected in the results. Girls were asked more academic questions, for example, 'If there are two ducks in the pond, then how many ducks are there altogether?', a finding which seems inconsistent with a research that has found teachers to ask boys more academic-related questions (She, 2000). Teachers also gave 
girls more responses that extended their thinking, for example a child tells the teacher she is filling a bottle with water and when the bottle is full the teacher responds to her: 'Let's see if the bottle will sink or float'. Girls also received more academic praise, a finding which also appears inconsistent with findings by Qureshi et al. (2007) of Pakistani girls being praised more for their quiet, compliant, passive behaviour. This finding reflects the teachers' views of girls' greater academic inclination and their desire to play an important role in the future development of their female students, given their own struggles. The teachers' own vulnerable position may have also influenced the praise they gave girls whose behaviour is often under critical scrutiny by others. Teachers appeared to go closer to girls than boys and touched girls more than boys. This finding seems to reflect consistency with the teacher's views described earlier about being more inclined towards girls because of their calm, well-mannered behaviour.

\section{Girls get more attention during play}

Figure 3 shows four types of teacher interactions which were compared to explore the differences in the number of teacher interactions with girls and boys during seven unstructured play episodes. The score for each category represents a cumulative count of various subcategories ${ }^{11}$ for each type of interaction which were used in the larger data set. In these four categories of interaction type, the gender difference was found to be significant only for teacher response $(t(4)=4.120, p<0.05)$. While the other categories did not show significant differences, girls had an edge over boys in all three categories.

The teachers indicated their preference for supporting children's play in the art, home and kitchen areas - areas predominantly selected by girls whose play reflected traditional gender images. The teachers' comfort in these areas and with 'girl-type' activity in these areas was rooted in their own interests and experiences with which they could connect as women engaged in similar roles from childhood. They felt less interested and less comfortable in the block-and-sand areas, the preferred choices of boys, and reported that they spent less time there. As one teacher described: 'Sand and blocks, these two areas (are) the boring ones ... I don't want to go into (these) areas somehow ... I don't feel very comfortable'. The teachers expressed their struggle with how to support children - usually boys - as they constructed and fixed things in the

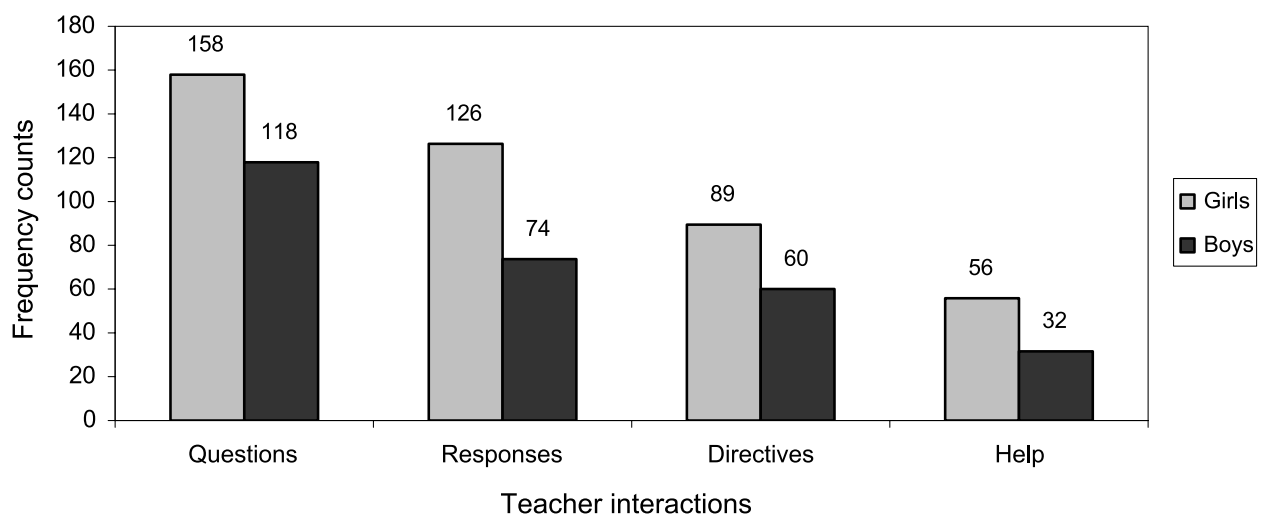

Figure 3. Teacher interactions with kindergarten girls and boys (play episodes). 
block area or filled and emptied bottles in the sand area. For example, one teacher shared the challenge she faces in determining how to "motivate the (children) to do different things (as) they keep on doing the same thing (in the sand area), filling up the bottle, then just making a mountain'. The teachers' own limited opportunity as young girls and women to engage in such experiences may have resulted in their sense of feeling incapable, having limited interest and experiencing difficulty facilitating such play activities. Their limited training in pre-primary education may have also further compounded this. The anecdotal observations confirmed the teachers' preferences of learning areas and activities during children's play. These findings suggest that if the children had had more opportunities for play, girls may have received more teacher attention than they currently do in the predominantly teacher-centred academic curriculum. These findings also seem to support teachers' perceptions of having more time to give to girls when boys are on-task and engaged in activities which they enjoy and which support their learning styles. Nevertheless, for a curriculum which included more opportunity for play to be transformative, it would be important for teachers to reflect critically on the prevalent gender structures that shape their own and their students' understanding of gender. As their current practice reflects, the teachers by and large reinforced the maintenance of existing gender patterns of behaviour.

\section{Teacher talk in the construction of young children's gender identities}

The teachers' influence over children's evolving gender identities was apparent in their choice of language (such as 'girl', 'boy', 'Aunty' or 'Uncle') which evoked gender in the organisation of everyday interactions. References to the roles of the children's mothers and fathers also reinforced messages about prevalent gender structures of male and female roles. Teachers reminded the children to take care of their mothers at home and aunties (teachers) at school during the holy month of Ramadan, ${ }^{12}$ when mothers and aunties would be tired because they have to wake up early in the morning to prepare the sehri, ${ }^{13}$ may likely be working and would have to prepare the ifftar ${ }^{14}$ and dinner while they were fasting all day.

The transmission of gender stereotypical notions was also evident during the teaching-learning process. For example, during an observation of a brainstorming activity as part of a creative writing lesson on the topic of Eid-ul-Fitr, ${ }^{15}$ the teachers asked children probing questions such as: 'Where did the boys go on Eid?' (Student responses: 'Masjid ${ }^{16}$ for namaz ${ }^{17}$ ), 'What did the girls do when the boys went to the masjid?' (Student responses: 'Help their mummies at home'); 'What did the girls wear?' (Student responses: 'Shalwar kameez', 'dress' or 'shahrarah'19,; 'bangles ${ }^{20}$ '); 'What did the girls have on their hands?' (Student responses: 'Mehndi ${ }^{21}$ '); and 'What did the boys wear?' (Student responses: 'Trousers', 'shirt' or 'shalwar kurta's'). There was laughter in the classroom, including the teacher, when a child mistakenly mentioned boys applying mehndi and wearing bangles, demonstrating how both teachers and children actively produced and reproduced gender divisions within the classroom culture.

Gender issues were rarely critically addressed or unpacked by the teachers with their students, and the study demonstrates the participants' unawareness of the implicit gender-biased messages to students in their practice. Similar findings have been found in Pakistan (Ashraf, 2007; Zainulabidin, 2007) and elsewhere (Liu, 2006; Skelton \& Francis, 2003). In the context of this study, this is not surprising given the kindergarten teachers' lack of training in gender issues. 


\section{Conclusion and implications}

This study explores the construction of young children's gender identities through teacher-student interactions in the early childhood classroom culture, a significant issue for Pakistan. Relatively few studies have attempted to explore early childhood teachers' role in shaping young children's evolving identities, and the present study provides new insights and understandings about this complex issue, situating them within the dominant gender ideologies of the broader society. As the findings show, teachers are actively engaged in producing and reproducing gender in the classroom through interactions which reveal the embeddedness of gender both in school culture and in the wider systems of meaning in society (Connell, 2006; Liu, 2006; Renold, 2006; Robinson \& Jones Diaz, 2006).

The teachers' perspectives have drawn attention to the key role that they play in making the classroom a space where gender norms can be perpetuated or where change can take place. In theory, the women kindergarten teachers have espoused relatively accepting views of non-stereotypical gender behaviours and have advocated equal opportunities for girls and boys. In practice, this has raised tensions for them and they seemed unprepared and, to a certain extent, unready to handle it. For the most part, their interaction with their students reveals their internalisation of dominant patriarchal values and their active role in perpetuating them. Boys remained more visible, more problematic academically and socially, and were given more teacher time. Girls remained largely invisible, more compliant and received less teacher time; academically, they performed more successfully and independently. Inconsistencies in classroom expectations due to a lack of training were problematic and contributed to male dominance in the classroom, at times frustrating the teachers and rendering them helpless. The study corroborates Paechter's (1998) argument that, despite growing global concern over boys' underachievement with improvements in girls' relative academic success, girls continue to face inequities in education. Nevertheless, as Liu (2006) points out, girls are not the only victims of stereotyping within school culture. Boys who do not conform to constructions of approved 'masculine' codes of conduct within contextual norms are also marginalised (Connell, 2006). Consequently, girls' and boys' differential treatment in the classroom through gendered teaching practice further reinforces gender identities.

The teachers' gendered practice has also presented evidence of possibilities for change in their unconscious and, occasionally, conscious attempts to push gender boundaries. Their messages to children sometimes challenge prevailing gender ideologies, and in certain instances, they seem open to considering alternate forms of being 'girl' and being 'boy'. Some evidence of girls' visibility in their play and in the greater frequency of teachers' academic questions and academic praise to them reflect ways in which teachers can challenge and disrupt stereotypical gender constructions. In this patriarchal context where girls remain largely vulnerable and disadvantaged, such actions are critical for girls' developing understanding of their gender identity and self-worth. Nevertheless, there appears to be a dilemma faced by teachers about following ascribed gender norms or allowing for more change in a context influenced by globalisation and socio-economic change. The study also points to the tensions faced by teachers in determining the extent to which they can push gender boundaries in the face of more dominant, prevailing forces.

This present study in the context of Pakistan highlights the need for further indepth exploration, both locally and more globally, of gendered teacher-student 
interactions in the early years of school life and how these interactions influence the construction of children's gender identities. As Liu has argued, it is also necessary to examine 'femininity and masculinity as relational and mutually dependent constructions rather than as isolated categories in research on gender and education' (2006, p. 435). Given the complexity in children's developing identity, further research into how the construction of children's gender identity is influenced by other markers of identity such as social class, ethnicity and religion is critical. An important outcome of such research would be to explore ways to make sound use of the research evidence for the purpose of change and to evaluate any intervention which takes place (Liu, 2006). As a first study in Pakistan, this research may also provide a modest foundation to illuminate and broaden understandings of gender in early childhood education. The study has shown interesting trends which can provide a baseline for future studies, including a larger study with diverse populations in this country.

The aspect of teacher training also requires re-examination in contexts like Pakistan. This study highlights the challenges women kindergarten teachers face in their practice generally and in relation to gender in particular, with access to little or no teacher education. Quality pre-service and in-service teacher education grounded in contemporary perspectives of childhood, child development and early childhood education practice is essential, as is the inclusion of a gender component which builds on research evidence and promotes critical reflection on this issue. More important is for teachers to become aware of the detrimental effects of gender bias and to locate their own and others' positions to ensure that sensitivity and equity are considered. Changes in school curricula are also necessary to ensure appropriate learning environments and practices for young children which consider gender equity and which reflect children's diverse experiences. It is critical when working with families and communities in highly gender-segregated contexts like Pakistan to understand the kinds of learning environments and practices which are in both girls' and boys' best interests, particularly in today's increasingly complex global world.

\section{Acknowledgements}

I wish to thank the school, teachers, children and parents for their participation in my research. I would also like to acknowledge grants from Social Sciences and Humanities Research Council, Canada (SSHRC) and the Ontario Institute for Studies in Education, University of Toronto (OISE/UT), which funded this research. The support from my doctoral supervisor and committee members has also facilitated the research process. I am also grateful to my three 'critical friends' for their review of this manuscript.

\section{Notes}

1. According to purdah, women veil themselves to varying degrees while moving in public areas such as markets, roads, public transport or public parks. Some women cover the whole body, including the face. Others use a shawl or scarf to cover their head and bosom.

2. In the Pakistani context, pre-primary schooling is generally considered schooling before Class 1. In this study, the researcher has used the term 'pre-primary' to refer to schooling in the early years, including kindergarten, before Class 1 .

3. Pseudonym.

4. The official language of the government is English.

5. The High/Scope Perry Preschool project, initiated in the 1960s by David Weikart as a research and curriculum development early intervention project, was aimed to help 'at risk' young children from poor neighbourhoods in Ypsilanti, Michigan. Today, the High/Scope 
approach is used in both urban and rural settings worldwide. Pakistan's National Curriculum for Early Childhood Education implemented in 2002 and revised in 2007 draws on components of the High/Scope approach.

6. In the research site, the 'plan-work-recall' component of the High/Scope approach was adapted. During the 5- to 10-minute 'planning' time, children sat in a group and shared which learning areas they would go to and the work/play they would be engaged in. The 'work time', when children engaged in play in the various learning areas, lasted approximately 25-30 minutes. The learning areas included block, language/library, art, kitchen, water and sand. (Usually four areas were available for children to select on a given day.) The children then came back into a group for a 5- to 10-minute 'recall time', where they reflected upon what they had accomplished during the 'work time'.

7. There was no observation checklist available for use in this context, and it was important to develop a contextually relevant tool. Using a video recorder may have facilitated the process. However, given the cultural context where photographing and videoing women and girls are sometimes not permitted, the researcher felt that this might be challenging to manage from an ethical perspective.

8. These two categories were selected based on the highest frequency: most frequently observed.

9. In Pakistan, young children generally address their teachers as 'Aunty' in pre-primary school.

10. A long scarf that is draped across the bosom and shoulders and sometimes over the head; usually worn with a kameez (long, loose-fitting shirt) and shalwar (baggy, loose-fitting trousers).

11. The subcategories were: Questions (Academic Questions, Procedural Questions), Responses (Academic Responses, Procedural Responses, Extending Thinking), Directives (Academic - Learning Outcomes, Academic - Instructions, Procedural) and Help (Academic Help - Student Requested, Academic Help - Teacher Initiated, Procedural Help).

12. The ninth month in the Muslim calendar when most practising Muslims observe daily fasting and prayer.

13. During Ramadan, most Muslims observing the fast wake up before dawn to eat a meal known as sehri, a substantial meal considered to be important for sustaining a person until the fast ends.

14. At maghrib (sunset), Muslims partake in ifftar to break their fast. Traditionally, the fast is broken by eating dates just as the Prophet (PBUH) is believed to have done to break his fast. Thereafter, people partake in a delicious array of 'snack-type' food that is both sweet and savoury. Later in the evening and after maghrib prayers, dinner is eaten.

15. Eid-ul-Fitr is celebrated by Muslims around the world to mark the end of the holy month of fasting, Ramadan, with the sighting of the new moon. Among the majority of Muslim sects, boys and men go to the masjid (mosque) to offer special prayers called Eid namaz; women pray at home and are usually involved in preparing a special meal and other food items. It is a day when families and friends visit each other wearing their best clothes and exchanging sweets. Elders usually give children money as a gift for Eid.

16. A mosque is a Muslim place of worship/prayer.

17. Prayers.

18. A shalwar is a baggy, loose-fitting trouser and a kameez is a long, loose-fitting shirt. These are worn by women together with a dupatta.

19. A long, traditional skirt with a short blouse, complemented with a dupatta.

20. During Eid-ul-Fitr, it is a tradition for women to wear bangles. A few days before Eid, women and girls go shopping to buy bangles that match their new Eid outfits.

21. Henna.

22. The kurta is similar to a kameez (long, loose-fitting shirt worn by women) and is worn by boys and men.

\section{Notes on contributor}

Almina Pardhan is faculty at the Institute for Educational Development, Aga Khan University, Karachi, Pakistan. Her doctorate from OISE/University of Toronto, Canada, looked at gender issues in the context of early childhood education in Pakistan. Her teaching and research 
interests are in the areas of early childhood education and gender issues in education in diverse cultural contexts.

\section{References}

Ashraf, D. (2007). Shifting position and changing image: Women teachers' experiences in the northern areas of Pakistan. In R. Qureshi \& J. Rarieya (Eds.), Gender \& education in Pakistan (pp. 78-105). Karachi: Oxford University Press.

Bashiruddin, A. (2007). Becoming a teacher educator: A female perspective. In R. Qureshi \& J. Rarieya (Eds.), Gender \& education in Pakistan (pp. 43-59). Karachi: Oxford University Press.

Biklen, S.K., \& Pollard, D. (2001). Feminist perspectives on gender in classrooms. In V. Richardson (Ed.), Handbook of research on teaching (4th ed., pp. 723-748). Washington, DC: American Educational Research Association.

Blaise, M. (2005). Playing it straight: Uncovering gender discourses in the early childhood classroom. New York: Routledge.

Blaise, M. (2010). New maps for old terrain: Creating a postdevelopmental logic of gender sexuality in the early years. In L. Brooker \& S. Edwards (Eds.), Engaging play (pp. 80-95). Maidenhead: McGraw-Hill.

Brooker, L., \& Woodhead, M. (2008). Developing positive identities. Milton Keynes: Open University Press.

Children's Resources International. (2008). ECE policy review: Policies, profile and programs of early childhood education (ECE) in Pakistan. Pakistan: UNESCO and UNICEF.

Clarke, J., Hall, S., Jefferson, T., \& Roberts, B. (1976). Subcultures, cultures and class. In S. Hall \& T. Jefferson (Eds.), Resistance through rituals: Youth subcultures in post-war Britain (pp. 9-78). London: HarperCollins Academic.

Colwell, M.J., \& Lindsey, E.W. (2003). Teacher-child interactions and preschool children's perceptions of self and peers. Early Child Development and Care, 173(2-3), 249-258.

Connell, R.W. (2006). Understanding men: Gender sociology and the new international research on masculinities. In C. Skelton, B. Francis, \& L. Smulyan (Eds.), The SAGE handbook of gender and education (pp. 18-30). London: Sage.

Dobbs, J., Arnold, D.H., \& Doctoroff, G.L. (2004). Attention in the preschool classroom: The relationships among child gender, child misbehavior, and types of teacher attention. Early Child Development and Care, 174(3), 281-295.

Drudy, S., \& Chathain, M.U. (2002). Gender effects in classroom interaction: Data collection, self analysis and reflection. Evaluation and Research in Education, 16(1), 34-50.

Halai, A. (2007). Boys are better mathematicians! Gender issues in mathematics classrooms in Pakistan. In R. Qureshi \& J. Rarieya (Eds.), Gender and education in Pakistan (pp. 109-125). Karachi: Oxford University Press.

Hyun, E. (2007). Cultural complexity in early childhood: Images of contemporary young children from a critical perspective. Childhood Education, 83(5), 261-266.

Hyun, E., \& Tyler, M. (2000). Examination of early childhood practitioners' general perception of gender differences in young children. Journal of Early Childhood Teacher Education, 21(3), 337-354.

Jackson, P. (1989). Maps of meaning: An introduction to cultural geography. London: Routledge.

Jayasuriya, L. (2008). Constructions of culture and identity in contemporary social theorizing. International Journal of Culture and Mental Health, 1(1), 30-43.

Liu, F. (2006). School culture and gender. In C. Skelton, B. Francis, \& L. Smulyan (Eds.), The SAGE handbook of gender and education (pp. 425-438). London: Sage.

Mac an Ghaill, M. (1994). The making of men: Masculinities, sexualities, and schooling. Buckingham: Open University Press.

MacNaughton, G. (2000). Rethinking gender in early childhood education. London: Paul Chapman Publishing.

Miles, M.B., \& Huberman, A.M. (1994). Qualitative data analysis: An expanded sourcebook (2nd ed.). Thousand Oaks, CA: Sage. 
Ministry of Education. (2003). National Plan of Action on Education for All (2001-2015) Pakistan. Islamabad: Government of Pakistan.

Miske, S., \& VanBelle-Prouty, D. (1997). Schools are for girls too: Creating an environment of validation (Technical paper no. 41). Washington, DC: Research and References Service Project, USAID.

Paechter, C.F. (1998). Educating the other: Gender, power, and schooling. London: Falmer Press.

Penn, H. (2005). Understanding early childhood: Issues and controversies. Berkshire: Open University Press.

Qureshi, R., Prizado, P., \& Nasim, S. (2007). Schooling in rural Sindh. In R. Qureshi \& J. Rarieya (Eds.), Gender \& education in Pakistan (pp. 126-146). Karachi: Oxford University Press.

Renold, E. (2006). Gendered classroom experiences. In C. Skelton, B. Francis, \& L. Smulyan (Eds.), The SAGE handbook of gender and education (pp. 439-452). London: Sage.

Robinson, K.H., \& Jones Diaz, C. (2006). Diversity and difference in early childhood education: Issues for theory and practice. Berkshire: Open University Press.

Rogoff, B. (2003). The cultural nature of human development. New York: Oxford University Press.

Schoen, L., \& Teddlie, C. (2008). A new model of school culture: A response to a call for conceptual clarity. School Effectiveness and School Improvement, 19(2), 129-153.

She, H.-C. (2000). The interplay of a biology teacher's beliefs, teaching practices and genderbased student-teacher classroom interactions. Educational Research, 42(1), 1-11.

Skelton, C., \& Francis, B. (2003). Boys and girls in the primary classroom. Berkshire: Open University Press.

Tantekin, F. (2002). The attitudes of early childhood teachers toward gender roles and toward discipline. (Unpublished doctoral dissertation). Florida State University College of Education, Tallahassee, FL, USA.

Tudge, J., \& Hogan, D. (2005). An ecological approach to observations of children's everyday lives. In S. Greene \& D. Hogan (Eds.), Researching children's experience approaches and methods (pp. 102-122). London: Sage.

UNESCO (United Nations Educational, Scientific and Cultural Organization). (2009). Overcoming inequality: Why governance matters (EFA Global Monitoring Report). Oxford: Oxford University Press.

Yelland, N., \& Grieshaber, S. (1998). Blurring the edges. In N. Yelland (Ed.), Gender in early childhood (pp. 1-14). London: Routledge.

Zainulabidin, N. (2007). Teachers' instructional practices in relation to their expectations of girls and boys in a co-education primary school in Pakistan. (Unpublished master's thesis). Institute for Educational Development, Aga Khan University, Karachi, Pakistan. 